\title{
DESEMPENHO AGRONÔMICO DE SOJA EM FUNÇÃO DA SUCESSÃO DE CULTURAS EM SISTEMA PLANTIO DIRETO ${ }^{1}$
}

\author{
Soybean agronomic performance as a function of crop sucession in no tillage system
}

\author{
Eduardo André Brandt'², Luiz Carlos Ferreira de Souza ${ }^{3}$, \\ Antonio Carlos Tadeu Vitorino ${ }^{3}$, Marlene Estevão Marchetti ${ }^{3}$
}

\begin{abstract}
RESUMO
Com o objetivo de avaliar o efeito da rotação ou sucessão de culturas sobre o desempenho agronômico de soja em semeadura direta, foi desenvolvido um experimento em Latossolo Vermelho distroférrico, no Núcleo Experimental de Ciências Agrárias da Universidade Federal de Mato Grosso do Sul, em Dourados - MS. O delineamento experimental foi em blocos casualizados com nove tratamentos e quatro repetições. As parcelas mediram $36 \mathrm{~m}$ de comprimento por $11 \mathrm{~m}$ de largura $\left(396 \mathrm{~m}^{2}\right)$, onde foram semeadas mecanicamente 26 linhas de soja, espaçadas entre si de $0,45 \mathrm{~m}$. Os tratamentos consistiram de nove sistemas de sucessão de culturas assim constituídos: Sistema 1: milho/ervilhaca/milho/ervilhaca/soja; Sistema 2: algodão/aveia/algodão/sorgo/soja; Sistema 3: soja/trigo/ soja/milho/milheto/soja; Sistema 4: milho/nabo/milho/sorgo/soja; Sistema 5: milho/aveia/milho/feijão/milheto/soja; Sistema 6: arroz/ nabo/arroz/aveia /soja; Sistema 7: arroz/sorgo/arroz/feijão/milheto/soja; Sistema 8: algodão/trigo/ algodão/trigo/soja e Sistema 9: algodão/ nabo/algodão/aveia/soja. Foi avaliada a massa seca da parte aérea das plantas de soja no estádio de florescimento pleno, a altura da planta e inserção da primeira vagem, o número de vagens por planta, a produtividade e a massa de 100 grãos. Concluiu-se que o sistema de rotação ou sucessão de culturas não influenciou na massa seca de plantas, altura de planta, inserção de vagem e número de vagens por planta de soja; por outro lado, a rotação arroz/sorgo/arroz/feijão/milheto/soja e a sucessão soja/trigo/soja/milho/milheto /soja proporcionaram à soja maior produtividade de grãos.
\end{abstract}

Termos para indexação: Sistemas de produção, produtividade, Glycine max.

\begin{abstract}
With the objective of evaluating the effect of crop rotation or succession on soybeans agronomic performance in no tillage system, an experiment was carried out in a distrophic Red Latosol, at the Núcleo Experimental de Ciências Agrárias da Universidade Federal de Mato Grosso do Sul, in the county of Dourados-MS. The experimental procedure was a randomized blocks design with nine treatments and four replications. The plots had 36 meters of length and 11 meters of width $\left(396 \mathrm{~m}^{2}\right)$, where were mechanically sawed 26 lines of soybeans, at intervals of 0,45 meters between lines. The treatments were composed of nine systems of crop succession: system 1: corn/vetch/corn/vetch/soybeans; system 2: cotton/oat/cotton/sorghum/soybeans; System 3: soybean/wheat/ soybeans/corn/millet/soybeans; system 4: corn/grazing turnip/corn/sorghum/soybeans; system 5: corn/oat/corn/beans/millet/soybeans; system 6: rice/grazing turnip/rice/oat/soybeans; system 7: rice/sorghum/rice/beans/millet/soybeans; system 8: cotton/wheat/cotton/ wheat/soybeans and system 9: cotton/grazing turnip/cotton/oat/soybeans. The dry matter of the aerial part of the soybean plants in full flowering stadium, plants height and first pod insertion, number of pods per plant, the productivity and the 100 grains mass, were evaluated. It was concluded that the crop rotation or crops succession was not influenced by the plant height, pods insertion and number of pods per plant. On the other hand, the rotation systems of rice/sorghum/rice/beans/millet/soybean and soybeans/wheat/ soybeans/corn/millet/soybean, provided the soybeans the higher grains yield.
\end{abstract}

Index terms: Crops rotation, productivity system, soybeans yield, Glycine max.

\section{(Recebido para publicação em 2 de junho de 2005 e aprovado em 21 de março de 2006)}

\section{INTRODUÇÃO}

A produção de grãos em Mato Grosso do Sul e, em especial na região de Dourados, está embasada na cultura da soja, que possui a maior área cultivada no Estado. A produtividade média que no início da exploração da cultura, era de $1403 \mathrm{~kg} \mathrm{ha}^{-1}$ (MELO FILHO \& RICHETTI, 1998) foi sendo incrementada em mais de $100 \%$, atingido na safra 2002/2003, valores na ordem de $2900 \mathrm{~kg} \mathrm{ha}^{-1}$ (CONAB, 2006). Esse significativo aumento está relacionado à incorporação de tecnologias ao processo de produção, dentre as quais destaca-se o plantio direto, que consiste no processo de semeadura sem o revolvimento do solo, no qual a semente é colocada em sulcos ou covas, com largura e profundidade suficientes para a adequada cobertura, sendo adotado por cerca de $70 \%$ dos produtores de Mato Grosso do Sul (MELO et al., 2001).

O ganho imediato resultante do sistema plantio direto foi a redução da erosão hídrica e sensível diminuição nos custos de produção, graças ao abandono do preparo

\footnotetext{
${ }^{1}$ Parte da dissertação do primeiro autor apresentada à Universidade Federal de Mato Grosso do Sul, como requisito à obtenção do título de Mestre em Agronomia, área de concentração: Produção Vegetal.

2 Engenheiro Agrônomo - COPERPLAN, Av. Aziz Rasselen, 66 - 79822-059 - Jardim Clímax - Dourados, MS - eduardo.coperplan@terra.com.br

${ }^{3}$ Professor Adjunto DCA - UFMS - Cx. P. 53 - 79804-970 - Dourados, MS - Icfsouza@ceud.ufms.br
} 
do solo com implementos de discos. Alguns problemas, porém, surgiram, em especial os relacionados à monocultura, tais como o aumento na incidência de pragas e doenças, dificuldade no controle de planta daninha e produção de palha insuficiente para adequada cobertura do solo.

Para que os benefícios do plantio direto sejam alcançados em sua plenitude faz-se necessário que ele seja entendido como um sistema de manejo conservacionista. Esse sistema envolve todas as técnicas recomendadas para aumentar a produtividade, conservando ou melhorando continuamente o ambiente e fundamenta-se na ausência de revolvimento do solo, na sua cobertura permanente e na rotação de culturas. Pressupõe, também, uma mudança na forma de pensar a atividade agropecuária, a partir de um contexto sócio-econômico, com preocupações ambientais (HERNANI \& SALTON, 1998). Visto desta maneira, o sistema de plantio direto é adotado por uma minoria de sojicultores da região sul de Mato Grosso do Sul, cuja prática usual é a sucessão soja/milho de safrinha.

Sendo a cultura da soja a mais importante no Estado de Mato Grosso do Sul e a rotação de culturas um fundamento do sistema plantio direto, o estudo de diferentes rotações ou sucessões de culturas adaptadas a essa condição de plantio, resultará em subsídios para adoção do plantio direto como sistema de produção com sustentabilidade.

Estudos desenvolvidos por Santos \& Reis (1990) concluíram que as culturas antecessoras tiveram efeito sobre a altura de plantas, número de vagens, número de grãos e peso de grãos por planta e peso de 1000 sementes. Observaram também que a soja cultivada em sucessão a colza apresentou menor produtividade.

A cultura antecessora de aveia-branca; aveia-preta; trigo e aveia-preta em consórcio com ervilhaca peluda não influenciou significativamente sobre a produção de grãos de soja, sob plantio direto, havendo abundante nodulação em soja em todos os sistemas de produção (FONTANELI et al., 2000).

Santos et al. (1997) estudaram o efeito de culturas de inverno e de sistemas de rotação de culturas sobre algumas características da soja, em sistema plantio direto. Verificaram que deve ser evitada a semeadura de soja após resteva de linho.

Portanto, o estudo de sistemas de produção envolvendo rotação de cultura é de fundamental importância para dar sustentabilidade técnica, ambiental e econômica ao setor agropecuário, principalmente, para sensibilizar os produtores e a assistência técnica para sua adoção. Neste sentido, o objetivo do presente trabalho foi de avaliar o desempenho agronômico da soja em diferentes sucessões de culturas em sistema plantio direto.

\section{MATERIAL E MÉTODOS}

Este experimento é parte de um projeto de longa duração que teve início em 1997, envolvendo produção de grãos baseada em sistemas de rotação ou sucessão de culturas. Os resultados apresentados neste trabalho são referentes aos obtidos no ano agrícola de 2000/01, realizado no Núcleo Experimental de Ciências Agrárias da Universidade Federal de Mato Grosso do Sul, localizado no município de Dourados - MS (latitude 22 ${ }^{\circ} 14^{\prime} \mathrm{S}$ e longitude 54⒋' $\mathrm{W}$ e $452 \mathrm{~m}$ de altitude), em solo classificado como Latossolo Vermelho distroférrico, originalmente sob vegetação de cerrado.

O delineamento experimental foi em blocos casualizados com nove tratamentos e quatro repetições. As parcelas mediram $36 \mathrm{~m}$ de comprimento por $11 \mathrm{~m}$ de largura $\left(396 \mathrm{~m}^{2}\right)$, onde foram semeadas mecanicamente 26 linhas de soja com $36 \mathrm{~m}$ de comprimento, espaçadas entre si de $0,45 \mathrm{~m}$.

Os tratamentos consistiram de nove sistemas de sucessão de culturas, envolvendo diferentes espécies vegetais, semeadas no outono/inverno de 2000, antecessoras à soja, conforme Quadro 1 . O referido quadro contém a sequiência de sucessão de culturas por tratamento, desde o verão de 1998 até o verão de 2000.

As culturas de outono/inverno foram semeadas em 28/04/2000, e as geadas ocorridas nos dias 13 e 25/07/2000 mataram as culturas de feijão, milho e sorgo, na fase de enchimento de grãos, e causou chochamento dos grãos na cultura de trigo. Essas culturas não foram colhidas, sendo manejadas com rolo faca no dia 05/09/2000 juntamente com a aveia preta e a ervilhaca peluda. Nas parcelas (Quadro 1) que continham feijão (tratamentos 5 e 6) e milho (tratamento 3), foram semeadas o milheto em 15/ 09/2000, sendo dessecado com os herbicidas glyphosate na dose de 2,0 $\mathrm{L} \mathrm{ha}^{-1}$ e 2,4-D amina na dose de $1,1 \mathrm{~L} \mathrm{ha}^{-1}$, no dia 01/11/2000.

A semeadura da soja ocorreu em 11/11/2000, utilizando-se a variedade EMBRAPA 133, cujas sementes foram tratadas com os fungicidas carbendazin (30g i.a) + thiran (70g i.a) por $100 \mathrm{~kg}$ de sementes, e inoculadas com Bradyrhizobium japonicum. A semeadura foi realizada utilizando-se uma semeadora equipada para plantio direto, com três linhas, espaçadas $0,45 \mathrm{~m}$ entre si, regulada para distribuir $350 \mathrm{~kg} \mathrm{ha}^{-1}$ de adubo da fórmula 02-20-20 mais zinco, e uma densidade de 18 sementes por metro linear, 
visando obter estande final de 14 plantas $\mathrm{m}^{-1}$. O controle de plantas daninhas foi em pós-emergência, utilizando-se os herbicidas Bentazon na dose de 1,0 $\mathrm{L} \mathrm{ha}^{-1}$ e Sethoxydim na dose de 1,2 $\mathrm{L} \mathrm{ha}^{-1}$. O controle de lagartas foi realizado com uma aplicação de Clorpirifós na dose de 0,250 L ha ${ }^{-1} \mathrm{e}$ de percevejos com uma aplicação de Metamidofós na dose de $0,50 \mathrm{~L} \mathrm{ha}^{-1}$.

\section{Determinações:}

Massa seca da parte aérea das plantas de soja: As amostragens foram feitas no florescimento pleno (R2), utilizando-se um retângulo com dimensões de 1,0 m x 0,5 $\mathrm{m}$, lançado aleatoriamente dentro de cada parcela por duas vezes. Após contagem das plantas presentes no interior do retângulo, as mesmas foram cortadas rente ao solo e levadas para secagem em estufa com circulação forçada de ar a $65^{\circ} \mathrm{C}$, até atingirem peso constante. $\mathrm{O}$ valor obtido foi oriundo da média entre as duas amostragens realizadas por tratamento e repetição, sendo a massa seca expressa em g planta ${ }^{-1}$ e $\mathrm{kg} \mathrm{ha}^{-1}$.

Altura de planta e inserção de primeira vagem: As alturas de planta e de inserção da primeira vagem foram determinadas no momento da colheita, medindo-se ao acaso, 10 plantas por repetição, dentro das mesmas duas linhas de $5 \mathrm{~m}$ de comprimento que foram colhidas para determinação da produtividade. Para a altura de planta, foi medida a distância entre o nível do solo até o ápice do caule e a altura de inserção da primeira vagem foi determinada pela distância entre o nível do solo e a inserção da primeira vagem no caule.

Número de vagens por planta: $\mathrm{O}$ número de vagens por planta foi determinado na colheita, contando-se ao acaso, dentro das mesmas duas linhas de $5 \mathrm{~m}$ de comprimento que foram colhidas para determinação da produtividade. $\mathrm{O}$ resultado final do número de vagens foi representado pela média dez plantas por tratamento e repetição.

Produtividade da soja: A produtividade de grãos foi determinada colhendo-se todas as plantas de duas linhas de $5 \mathrm{~m}$ de comprimento, correspondendo a uma área de 4,5 $\mathrm{m}^{2}$, amostradas ao acaso dentro da parcela. Para esta avaliação foram colhidas na parcela duas áreas de $4,5 \mathrm{~m}^{2}$, e os valores obtidos representou a médias das duas amostragens por tratamento e repetição. Após a trilhagem e limpeza, os grãos foram pesados em balança de precisão com duas casas decimais e, após a determinação do grau de umidade, corrigiu-se os valores para $13 \%$ de umidade, e expressos em $\mathrm{kg} \mathrm{ha}^{-1}$.

Massa de 100 grãos: Após a determinação da produtividade, pesou-se quatro amostras de 100 grãos de soja por repetição, em balança de precisão com três casas decimais. A massa de 100 grãos foi determinada pela média das quatro amostras.

Os dados de todas as avaliações foram submetidos à análise de variância e, para comparação das médias entre os tratamentos, foi utilizado o teste de Tukey a $5 \%$ de probabilidade.

QUADRO 1 - Seqüência de sucessão de culturas com espécies semeadas de verão, outono/inverno e primavera no período de 1998 a 2000.

\begin{tabular}{|c|c|c|c|c|c|c|}
\hline \multirow{3}{*}{$\begin{array}{c}\text { Tratamentos } \\
\text { com sucessão } \\
\text { de culturas }\end{array}$} & \multicolumn{6}{|c|}{ Ano } \\
\hline & \multirow{2}{*}{$\begin{array}{c}1998 \\
\text { verão }\end{array}$} & \multicolumn{2}{|c|}{..........1999........... } & \multicolumn{3}{|c|}{$\ldots \ldots \ldots \ldots \ldots \ldots \ldots . . . . . .2000 \ldots \ldots \ldots \ldots \ldots \ldots \ldots \ldots$} \\
\hline & & outono/inverno & verão & outono/inverno & primavera & Verão \\
\hline 1 & milho & ervilhaca & milho & ervilhaca & (1) & Soja \\
\hline 2 & algodão & aveia-preta & algodão & sorgo & $(1)$ & Soja \\
\hline 3 & soja & trigo & soja & milho & milheto & Soja \\
\hline 4 & milho & nabo & milho & sorgo & $(1)$ & Soja \\
\hline 5 & milho & aveia-preta & milho & feijão & milheto & Soja \\
\hline 6 & arroz & nabo & arroz & aveia-preta & $(1)$ & Soja \\
\hline 7 & arroz & sorgo & arroz & feijão & milheto & Soja \\
\hline 8 & algodão & trigo & algodão & trigo & (1) & Soja \\
\hline 9 & algodão & nabo & algodão & aveia-preta & (1) & Soja \\
\hline
\end{tabular}

(1) Ausência de cobertura de primavera. 


\section{RESULTADOS E DISCUSSÃO}

Não houve diferença significativa $(\mathrm{p}<0,05)$ entre os sistemas de sucessão de culturas para produção de massa seca de planta de soja no estádio R2 (Quadro 2).

Blank (1993) estudou o acúmulo da massa seca de plantas de soja em função de doses de nitrogênio, nos estádios V8 a R1, nas cultivares Cristalina, IAC 8 e Doko, verificou que a massa seca variou entre $3.947 \mathrm{e}$ $5.076 \mathrm{~kg} \mathrm{ha}^{-1}$. O acúmulo da massa seca da parte aérea da planta de soja é dependente da altura da planta, que, por sua vez, varia em função do genótipo e do ambiente. No sistema plantio direto é importante a cultivar apresentar, além de boa produtividade de grãos, uma boa quantidade de palha no momento da colheita. A produção de massa seca obtida neste experimento em todos os sistemas de sucessão de cultura foi superior a 3 toneladas por hectare (Quadro 2), embora grande parte das folhas caia próximo da maturação fisiológica, com rápida decomposição.

Silva \& Rosolem (2002) obtiveram maior produção de massa seca da parte aérea das plantas soja, determinada aos 28 dias após a emergência, na sucessão ao tremoçoazul em relação ao milheto, soja e sorgo.

A altura de planta e a altura da inserção das primeiras vagens não diferiram estatisticamente entre os sistemas de sucessão de culturas. Os valores obtidos para estas duas características (Quadro 3), independente dos sistemas de sucessão de cultura, são considerados adequados para colheita mecânica, pois segundo Cartter \& Hartwing (1962) e Yokomizo (1999), a planta de soja com altura média entre 60 e $80 \mathrm{~cm}$ e, altura de inserção de vagem em torno de 12 a $15 \mathrm{~cm}$ permite uma eficiente colheita mecanizada, diminui o risco de acamamento e de perdas na colheita.

Resultados de pesquisa desenvolvida em Passo Fundo, RS, nas safras de 1983/84 à 1987/88, evidenciaram que a soja em sucessão ao trigo e ao linho apresentou maior estatura de plantas, em relação às antecedidas por tremoço e colza, e que a altura de inserção de vagens não diferiu em função das culturas antecessoras a soja (SANTOS \& REIS, 1990).

$\mathrm{O}$ número de vagens por planta não diferiu estatisticamente pelo teste $\mathrm{F}$ independente do sistema de rotação ou sucessão adotado. O número de vagens por planta foi em torno de 35 vagens, indicando a necessidade de maior estande para compensar na produtividade de grãos. Outros estudos também encontraram números de vagens por planta semelhante os obtidos nesta pesquisa, dos quais, Santos \& Reis (1990) obtiveram: 28,2 vagens por planta com a cultivar BR 4; Santos et al. (1991) 33,34 vagens por planta estudando as cultivares BR6, Bragg e BR 13 e entre 40 a 62 vagens por planta (NAVARRO JÚNIOR \& COSTA, 2002), com as cultivares FT 2003, OCEPAR 14, BR 16, RS 7- Jacuí, RS 9-Itaúba e CEP 20.

Observou-se diferenças significativas $(\mathrm{p}<0,05)$ para produtividade de grãos e massa de 100 grãos. A maior produtividade foi obtida nos sistemas 7 (arroz/sorgo/arroz/ feijão/milheto/soja) e 3 (soja/trigo/soja/milho/milheto/soja), significativamente superiores aos valores encontrados para o sistema 5 (milho/aveia/milho/feijão/milheto/soja), conforme Quadro 3.

QUADRO 2 - Valores médios da massa seca da parte aérea da planta de soja (g planta-1 $\mathrm{e} \mathrm{kg} \mathrm{ha}^{-1}$ ) no estádio R2, nos diferentes sistemas de sucessão de culturas.

\begin{tabular}{|c|c|c|}
\hline Sucessão de Culturas & Massa seca $\left(\mathbf{g ~ p l a n t a}^{\mathbf{- 1}}\right)^{\mathbf{1}}$ & Massa seca $^{\left(\mathbf{k g ~ h a}^{\mathbf{- 1}}\right)^{\mathbf{1}}}$ \\
\hline 1 & 15,29 & 4.587 \\
\hline 2 & 11,57 & 3.471 \\
\hline 3 & 15,58 & 4.674 \\
\hline 4 & 13,47 & 4.041 \\
\hline 5 & 16,32 & 4.896 \\
\hline 6 & 11,59 & 3.477 \\
\hline 7 & 12,95 & 3.885 \\
\hline 8 & 12,42 & 3.726 \\
\hline 9 & 14,19 & 4.257 \\
\hline
\end{tabular}

${ }^{1}$ não-significativo pelo teste $\mathrm{F}$ ao nível de $5 \%$ de probabilidade.

Ciênc. agrotec., Lavras, v. 30, n. 5, p. 869-874, set./out., 2006 
QUADRO 3 - Altura de planta $(\mathrm{cm})$, altura de inserção da primeira vagem $(\mathrm{cm})$, número de vagens por planta, produtividade de grãos $\left(\mathrm{kg} \mathrm{ha}^{-1}\right)$ e massa de 100 grãos (g) para a cultura da soja, em função dos sistemas de sucessão de culturas.

\begin{tabular}{|c|c|c|c|c|c|}
\hline $\begin{array}{c}\text { Sistemas de } \\
\text { sucessão de } \\
\text { culturas } \\
\end{array}$ & $\begin{array}{c}\text { Altura de } \\
\text { Planta }{ }^{1}\end{array}$ & $\begin{array}{c}\text { Altura de } \\
\text { inserção da } 1^{\text {a }} \\
\text { vagem }^{1} \\
\end{array}$ & $\begin{array}{c}N^{0} \text { de vagens } \\
\text { por planta }{ }^{1}\end{array}$ & Produtividade $^{2}$ & $\begin{array}{c}\text { Massa de } 100 \\
\text { grãos }^{2}\end{array}$ \\
\hline 1 & 75,00 & 17,25 & 36,82 & $2389,22 \mathrm{ab}$ & $13,38 \mathrm{~b}$ \\
\hline 2 & 83,50 & 19,5 & 38,35 & $2711,22 \mathrm{ab}$ & $15,65 \mathrm{a}$ \\
\hline 3 & 75,75 & 17,75 & 38,85 & $2791,67 \mathrm{a}$ & $14,78 \mathrm{ab}$ \\
\hline 4 & 73,5 & 16,25 & 34,52 & $2771,56 \mathrm{ab}$ & $14,72 \mathrm{ab}$ \\
\hline 5 & 81,75 & 18,25 & 33,87 & $2174,67 \quad b$ & $14,07 \mathrm{ab}$ \\
\hline 6 & 78,25 & 18,00 & 34,40 & $2352,78 \mathrm{ab}$ & $15,18 \mathrm{ab}$ \\
\hline 7 & 80,00 & 18,00 & 38,57 & $2799,83 \mathrm{a}$ & $15,15 \mathrm{ab}$ \\
\hline 8 & 74,25 & 16,75 & 36,75 & $2703,39 \mathrm{ab}$ & $14,99 \mathrm{ab}$ \\
\hline 9 & 75,50 & 18,00 & 33,35 & $2277,28 \mathrm{ab}$ & $14,40 \mathrm{ab}$ \\
\hline
\end{tabular}

${ }^{1}$ não-significativo pelo teste $\mathrm{F}$ ao nível de $5 \%$ de probabilidade.

${ }^{2}$ Médias seguidas pela mesma letra na coluna não diferem entre si pelo teste de Tukey a $5 \%$ de probabilidade.

O maior valor para massa de 100 grãos foi verificado na soja semeada sobre a cultura do sorgo no sistema 2 , significativamente superior ao encontrado na soja em sucessão a ervilhaca do sistema 1 (Quadro 3). De acordo com Santos et al. (1991), as massas de 100 grãos, juntamente com o número de vagens por planta não foram influenciadas pelas restevas de inverno. Os valores encontrados para massa de 100 grãos estão próximos dos obtidos por Navarro Júnior \& Costa (2002), que variaram entre 11,96 g e 15,42 g, em estudos envolvendo seis cultivares de soja no município de Eldorado do Sul, RS, na safra 1996/97.

\section{CONCLUSÕES}

a) A rotação ou sucessão de culturas não influenciou na produção de massa seca da parte aérea, altura de planta, inserção de vagem e número de vagens por planta de soja.

b) A rotação arroz/sorgo/arroz/feijão/milheto/soja e a sucessão soja/trigo/soja/milho/milheto/soja proporcionaram à cultura da soja maior produtividade de grãos.

\section{REFERÊNCIAS BIBLIOGRÁFICAS}

BLANK, A. F. Maximização da exploração da soja (Glycine $\max ($ L.) Merril): efeito da adubação nitrogenada no plantio e em cobertura na produção de feno e grãos oriundos da rebrota. 1993. 61 f. Dissertação (Mestrado) Escola Superior de Agricultura de Lavras, Lavras, 1993.
CARTER, J. L.; HARTWING, E. E. The management of soybeans. In: NORMAN, A. G. (Ed.). The soybean. New York: Academic, 1962.

CONAB. Série histórica de produtividade. Disponível em: $\langle$ http://Www.conab.gov.bri . Acesso em: 21 fev. 2006.

FONTANELI, R. S.; SANTOS, H. P. dos; VOSS, M.; AMBROSI, I. Rendimento e nodulação de soja em diferentes rotações de espécies anuais de inverno sob plantio direto. Pesquisa Agropecuária Brasileira, Brasília, v. 35, n. 2, p. 349-355, 2000.

HERNANI, L. C.; SALTON, J. C. Algodão: informação tecnológica. Dourados: Embrapa-CPAO, 1998. 267 p. (Circular técnica, 7).

MELO FILHO, G. A. de; RICHETTI, A.Perfil socioeconômico e tecnológico dos produtores de soja e milho de Mato Grosso do Sul. Dourados: Embrapa-CPAO, 1998. 57 p. (Documentos, 15).

MELO FILHO, G. A. de; VIEIRA, C. P.; RICHETTI, A.; NOVACHINSKI, J. R. Recomendação e nível de adoção de tecnologias agrícolas em Mato Grosso do Sul. Dourados: Embrapa Agropecuária Oeste, 2001. 76 p.

NAVARRO JÚNIOR, H. M.; COSTA, A. C. Contribuição relativa dos componentes do crescimento para produção de grãos de soja. Pesquisa Agropecuária Brasileira, Brasília, v. 37, n. 2, 2002. 
SANTOS, H. P. dos; LHAMBY, J. C. B.; SANDINI, I. Efeito de culturas de inverno e de sistema de rotação de culturas sobre algumas características da soja. Pesquisa Agropecuária Brasileira, Brasília, v. 32, n. 11, p. 11411146, 1997.

SANTOS, H. P. dos; REIS, E. M. Efeito de culturas de inverno sobre o rendimento de grãos e sobre algumas características agronômicas da soja. Pesquisa Agropecuária Brasileira, Brasília, v. 25, n. 11, p. 1637 1645, 1990.

SANTOS, H. P. dos; VIEIRA, S. A.; PEREIRA, L. R.; ROMAN, E. S. Rotação de culturas: efeito de sistemas de cultivo no rendimento de grãos e outras características agronômicas das plantas de soja. Pesquisa Agropecuária Brasileira, Brasília, v. 26, n. 9, p. 1539-1549, set. 1991.

SILVA, R. H. da; ROSOLEM, A. C. Crescimento radicular de soja em razão da sucessão de cultivos e compactação do solo. Pesquisa Agropecuária Brasileira, Brasília, v. 37, n. 6, 2002.

YOKOMIZO, G. K. Interação genótipos x ambientes em topocruzamentos de soja tipo alimento com tipo grão. 1999. $170 \mathrm{f}$. Tese (Doutorado) - Escola Superior de Agricultura "Luis de Queiroz", Piracicaba, 1999. 